\title{
Encontro entre Brasil e China: cooperação para o século XXI
}

\author{
SEVERINO CABRAL*
}

\section{Introdução}

"Sabendo reconhecer as prioridades, estarás ao alcance da Via”.

DaXue

O ano de 1999 assistiu a três significativos acontecimentos na história das relações sino-brasileiras. O primeiro deles foi a comemoração no mês de agosto do $25^{\circ}$ aniversário do estabelecimento de relações diplomáticas entre os dois países. Menos de meio século transcorreu desde o momento em que o Presidente Ernesto Geisel, aconselhado pelo chanceler Azeredo da Silveira, transformou um encontro de trabalho com uma missão comercial chinesa que visitava o país, no decisivo ato de reconhecimento pelo Brasil da existência política de um Estado que governava uma quarta parte da humanidade. Desde este momento, afirmaram-se relações baseadas em convergências no plano mais alto da política internacional. Sobretudo, germinou a idéia de que o novo século que se inaugura traz consigo desafios que devem ser respondidos de maneira conjunta pelos dois maiores países do mundo em desenvolvimento, de modo a contribuírem decisivamente para a criação de um mundo multipolar.

O segundo acontecimento, que despertou atenção generalizada do mundo da ciência e da técnica, foi o lançamento do satélite de sensoriamento sino-brasileiro. Construído pelos dois países, o satélite de levantamento de recursos naturais (Chinese-Brazilian Earth Resources - CBERS), lançado por um foguete chinês da série "Longa Marcha”, aparece como um terceiro sistema, rompendo, em setor tão decisivo para o conhecimento do nosso ambiente e das nossas riquezas naturais, o monopólio dos norte-americanos e dos europeus. Desse modo, o Brasil, com a cooperação da China, deu o seu primeiro e decisivo passo na era espacial. 
O terceiro acontecimento sino-brasileiro do ano de 1999, organizado pelo Embaixador Samuel Pinheiro Guimarães, Diretor do Instituto de Pesquisa de Relações Internacionais - IPRI, da Fundação Alexandre de Gusmão, reuniu e mobilizou acadêmicos, empresários, políticos, altos funcionários estatais e diplomatas dos dois países no Seminário Brasil-China. Realizado no Rio de Janeiro, nos dias 18 e 19 de novembro, nas dependências do Hotel Méridien, foi o primeiro grande encontro de intelectuais chineses e brasileiros, destinado a marcar uma data no processo de aproximação e mútuo conhecimento brasileiro-chinês.

Poder-se-ia acrescentar dois outros acontecimentos que também repercutiram no âmbito das relações sino-brasileiras, como de resto interessaram ao conjunto da Comunidade Internacional. Trata-se do cinqüentenário da fundação da Republica Popular da China e o retorno de Macau à soberania chinesa. Acontecimentos de marca, nesse ano de 1999, que representam uma simbólica retomada pela China de seu papel protagônico mundial.

A reemergência da Grande China frente ao Ocidente, que se completa com a retomada de Macau 452 anos depois de estabelecido o domínio luso na região, faz relembrar, por sua vez, outro acontecimento a ser registrado neste começo de ano 2000: a comemoração dos 500 anos da História do Brasil, inaugurada com a viagem do navegador português Pedro Álvares Cabral.

A irrupção no cenário mundial da República Popular da China, como definiu o seu fundador, Presidente Mao Zedong, significou que a China se pôs de pé. Nestes últimos 50 anos, muitas mudanças ocorreram no mundo. A Guerra Fria acabou, a China reformou-se e abriu-se ao mundo sem que a Nova República, e o mandato que o governante chinês lhe criou, se desfizesse. A terceira geração, nucleada em torno do Presidente Jiang Zemin, segue a linha política básica traçada pelo sucessor de Mao. Linha desenvolvida por Deng Xiaoping, o arquiteto-geral da reforma e abertura, que formulou a concepção do novo modelo chinês de desenvolvimento que se tornou conhecido como "teoria Deng Xiaoping do socialismo com peculiaridade chinesa”.

Muita coisa tem sido escrita e muita reflexão tem sido feita no Ocidente sobre estes acontecimentos que moldaram o destino da nação mais populosa do mundo. Independentemente do viés, pró ou contra, que adotam em sua interpretação, todos os que analisam a questão reconhecem a importância decisiva do acontecimento e sua repercussão nos próximos e decisivos anos do novo século.

O retorno de Macau à soberania chinesa, logo depois de Hong Kong, simboliza o fim de uma era de humilhações sofridas pela nação chinesa, mas também significa o desafio de dar continuidade, nestas paragens em que Ocidente e Oriente se reuniram ao longo de gerações, ao diálogo entre as civilizações. Neste encontro, mais uma vez reponta o fato de que a primeira presença Ocidental que marcou a cultura e o cotidiano da China, desde a introdução do budismo na altura do século I de nossa era, foi o esforço missionário e civilizatório do catolicismo português, que pouco antes havia se deparado com a existência do Brasil. 
Eco de uma ressurgência finissecular, parece que o destino de Macau, como ponto de encontro da cultura multimilenar da China com a cultura latina, é o de lançar uma ponte para o Extremo Ocidente, onde o Brasil surge como o gigante da lusofonia, responsável, com os seus 160 milhões de habitantes, pelo fato de ser o português, o terceiro mais falado idioma de cultura no Ocidente. Do lado chinês, cujo esforço em prol de seu desenvolvimento surpreende o mundo, os progressos extraordinários na assimilação da ciência e da técnica ocidentais não deverão fazer desaparecer o patrimônio de conquistas com que sua cultura clássica ainda maravilha e encanta a humanidade, mas sim reintegrá-la na construção de novas e mais avançadas formas culturais e civilizacionais.

No que a Nova China, que se desenvolve em ritmo acelerado, encontra o Brasil é na caminhada em busca de uma superação dos impasses ainda existentes no mundo do após-Guerra Fria. Trata-se de uma conjuntura internacional dominada por injunções hegemonistas, que tentam impor a via da unipolaridade e do “pensamento único”. Quem sabe, estará destinado ao diálogo sino-brasileiro, que se instaura e se adensa, por seus próprios esforços, dar à História, como queria Toynbee: “(...) algum giro novo e sem precedentes”?

Neste sentido, o Seminário Brasil-China, sob os auspícios do IPRI, esteve voltado, nos dias 18 e 19 de novembro de 1999, para o debate do futuro das relações de cooperação bilaterais, demarcando quatro áreas de atuação, verdadeiras avenidas temáticas abertas aos pesquisadores dos dois países. As dimensões chave, abordadas a partir de diferentes perspectivas, foram as seguintes: "Ciência e Tecnologia: políticas nacionais e possibilidades de cooperação”; "Energia: políticas nacionais e possibilidades de cooperação”; “A China e o Brasil na política internacional”; “A China e o Brasil na globalização”.

\section{Ciência e Tecnologia:}

\section{saber-poder, medição de forças e possibilidades de cooperação}

"Se a partir dos anos 60, a China não houvesse chegado a possuir bombas atômicas
e de hidrogênio, nem lançado satélites, não poderia chamar-se grande potência,
de significativa influência, nem deter a posição internacional que tem agora.”

Deng Xiaoping

Vivemos uma época de enormes transformações, que enfrenta desafios inéditos, resultantes do extraordinário desenvolvimento do novíssimo espírito científico e técnico associado à gigantesca massa de recursos e meios financeiros. Como no início dos tempos modernos, observa-se verdadeira mudança de pele do conjunto da humanidade. ${ }^{2}$ 
O “curto”(apud Hobsbawn) ou “longo”(apud Arrighi) século XX parece, à observação do aqui e agora, ter assistido a consumação de três revoluções de impacto mundial: a revolução científico-técnica; a revolução industrial; e a revolução política, liberal, nacional e social. Esta última, cujo marco foi a "Grande Revolução de 1989", teve o seu desdobramento máximo a partir dos Oitocentos, com as guerras napoleônicas e as suas consequêencias.

Entre as consequêências das guerras napoleônicas encontra-se a primeira vaga das independências das Américas, da qual resultou a emergência do Brasil; o concerto europeu pós-napoleônico; e o acordo anglo-francês de controle das rotas oceânicas mundiais, que levou as duas potências européias ao exercício de um condomínio sobre o "Império do Meio" e de vastas áreas do ecúmeno mundial. Este acordo, ao estabelecer a unificação do mercado mundial sob a forma da hegemonia inglesa e de uma nova colonização do mundo não europeu, prefigura o atual momento finissecular vivido pela "globalização" anglo-americana do mundo: da Pax Britânica, nos Oitocentos, à Pax Americana, nos Novecentos.

Vemos, pois, ressurgir neste fim de século e de milênio o espectro do neocolonialismo, sob o manto das transformações operadas pelo desenvolvimento da Revolução científica e técnica. Pretextando o domínio das altas tecnologias, baseadas nos recursos da ciência mais avançada da nossa época, os Estados Unidos da América - EUA - e seus associados impõem ao mundo em desenvolvimento um alto preço na alocação do capital e no financiamento à transferência desses recursos. Esta Política se traduz no endividamento e na permanente limitação à soberania e independência dos países que não detém a posse dessa força produtiva primacial (a Ciência e a Tecnologia), ameaçando-os conseqüentemente com a recolonização "global".

Por outro lado, se recuamos um pouco o ponto de fixação do observador, vemos que o conflito inaugurado pelo segundo após guerra (a Guerra Fria) fora marcado pelo advento da idade atômica, dando início à revolução mais ampla nos processos ligados à transformação da natureza da guerra. Essa transformação nos meios científicos e técnicos de produção de armamentos possibilitou o aparecimento de armas de destruição em massa de caráter absoluto (nucleares e termonucleares). A década seguinte assistiria ainda ao surgimento dos mísseis balísticos intercontinentais e dos satélites artificiais, os quais, associados ao aparecimento dos computadores e dos sistemas de informação eletrônicos altamente desenvolvidos, consolidariam o novo macroclima internacional, caracterizado pelo impasse atômico e o equilíbrio do terror.

Este cenário não se alterou com o fim da Guerra Fria, permanecendo de pé o princípio de que a medição de forças internacional contemporânea se trava em torno da posse e uso do conhecimento cientifico e técnico em prol do crescimento e do fortalecimento econômico das Nações. Operou-se, contudo, um deslocamento no quadro, com o desaparecimento da URSS e a concentração do poder mundial 
nas mãos dos dirigentes norte-americanos, pondo fim à bipolaridade e dando início ao processo de criação de uma nova ordem mundial.

Neste contexto, em que o antagonismo Norte-Sul se acentua, é que se insere a cooperação sino-brasileira no campo da ciência e tecnologia. Esta desenvolveu-se sobretudo no campo aeroespacial, em que foi alcançado importante resultado com o lançamento do satélite de levantamento dos recursos da terra, de construção conjunta, por um foguete chinês da série Longa Marcha. A construção e o lançamento exitoso do satélite sino-brasileiro permitiu aos dois países romperem o monopólio dos EUA e da União Européia - UE - no domínio da técnica do monitoramento dos recursos da terra, acontecimento que, além de introduzir o Brasil na era espacial, demonstra a possibilidade de união e solidariedade dos países do mundo em desenvolvimento na exploração comum dos recursos do espaço e na aquisição dos avanços da mais alta ciência e tecnologia. ${ }^{3}$

Algumas questões, suscitadas pelos aspectos políticos e legais da cooperação espacial sino-brasileira e pelas expectativas que ela abre para novos passos decisivos no umbral do novo milênio, têm sido examinadas e avaliadas, em diversas intervenções, por pesquisadores, autoridades políticas e cientistas dos dois países. Todos são unânimes em reconhecer a relevância do processo em curso, cuja dinâmica parece introduzir novas e inéditas configurações nos domínios da pesquisa avançada nas ciências da vida, da automação, biotecnologias, novos materiais e outras, que ampliam o quadro da cooperação e demonstram o bem fundado das palavras do Presidente Jiang Zemin, ao considerar que "o desenvolvimento conjunto do satélite sino-brasileiro de rastreamento dos recursos da terra (CBRES) é um modelo de cooperação entre países em desenvolvimento (um modelo de cooperação Sul-Sul)”.

Nessa linha de continuidade de esforços, a cooperação sino-brasileira projeta-se em direção ao século XXI, na exploração conjunta do espaço cósmico, com o lançamento dos primeiros satélites destinados ao monitoramento dos recursos da terra. Como é do conhecimento dos dirigentes dos dois países, a questão ambiental vem sendo usada pelos governos do G-7 como uma forma de intervenção política nos processos econômicos das nações do Sul. Desse modo, cresce em importância a ruptura do monopólio da técnica de sensoriamento remoto em decorrência do intercâmbio cientifico e técnico entre o Brasil e a China.

Não por acaso, o encontro Brasil-China teve um dos seus pontos altos no intercâmbio de idéias que representantes de instituições importantes dos dois países, como a Agência Nacional do Espaço da China, o Instituto Nacional de Pesquisas Espaciais do Brasil, a FIOCRUZ, o Instituto Butantã, a Embrapa e a Academia de Ciências da China, desenvolveram durante o seminário patrocinado pelo IPRI. Algumas de suas projeções deverão orientar os próximos passos para uma comunicação ainda maior entre os dois parceiros no terreno cientifico e técnico. 


\section{Energia: assegurar o desenvolvimento e aumentar o poderio nacional}

"Na atualidade, o mundo encara dois problemas: a paz e o desenvolvimento. Há esperanças de paz, porém, não se resolveu ainda o problema do desenvolvimento. Todo mundo diz que o problema Norte-Sul é muito agudo, e a mim me parece que aí reside precisamente o problema do desenvolvimento”. Deng Xiaoping

Pode-se inferir a importância capital que assume hoje a cooperação sinobrasileira no campo da produção de energia quando se pensa que a maior usina produtora de energia elétrica do mundo, construída pelo Brasil nos anos 70, serviu e serve de inspiração e modelo para a China erguer a usina de "Três Gargantas". Ao se concluir, será duas vezes e meia maior que "Itaipu”.

Como é conhecido, a construção de Itaipu acompanhou o processo de aceleração do crescimento industrial brasileiro, servindo de sustentáculo ao desenvolvimento do país em sua fase mais dinâmica. A emergência da maior usina hidroelétrica do mundo no sul do Brasil permitiu a consolidação nesta região do país do maior complexo industrial-urbano abaixo da linha do equador.

Deve-se imaginar que o desenvolvimento chinês, acelerado desde a reforma e abertura iniciada em 1978, tenha exigido a ampliação da produção de energia, tal como ocorrera no caso brasileiro. Daí a necessidade da construção da imensa barragem de "Três Gargantas". Esta exigência se evidencia, sobretudo quando se pensa que a interiorização do desenvolvimento da China permanece o desafio maior para os seus planejadores governamentais.

De igual modo, o Brasil também se depara, neste começo de milênio, com a necessidade de interiorizar o seu desenvolvimento e de completar a integração de vastas áreas do seu território ao ecúmeno nacional, sobretudo quando se depara com um quadro externo de pressões crescentes das grandes potências industriais, reunidas sob a forte e onipresente liderança norte-americana nas organizações internacionais (Comissões da ONU, Banco Mundial, FMI e OMC), e que se afirmam todas com um caráter claramente (re)colonizador, sob color da "globalização”.

Do que se depreende, com um sentido de urgência maior a cada ano que passa, o fato de que a imensa região amazônica e o nordeste brasileiro impõem um aumento no ritmo de crescimento e de acumulação de capitais e técnicas para que se proceda a sua inserção plena no conjunto da economia do país, tal como na China, onde as vastidões do Xinjiang, Mongólia, Tibet e das grandes províncias rurícolas internas, desafiam a imaginação e exigem a multiplicação dos esforços das autoridades centrais para que o seu desenvolvimento se consolide e as pressões externas se diluam. Tarefas comuns, portanto, questões cruciais postas aos dirigentes tanto da China como do Brasil, e que estão a exigir respostas eficazes e eficientes na defesa da soberania e da integridade de seus respectivos países. 
É neste sentido que os dois países podem pensar no futuro da cooperação econômica, particularmente no campo do intercâmbio energético. Trata-se, pois, de saber utilizar os recursos comuns sino-brasileiros na busca de novos campos e áreas de exploração de petróleo e gás natural, além de assegurar a possibilidade de um intercâmbio maior na área nuclear.

Os investimentos no domínio da exploração dos recursos energéticos de China e Brasil devem ser considerados como uma ação comum voltada para a criação de uma base de sustentação do desenvolvimento dos dois maiores países do mundo em desenvolvimento. Parte do planejamento nesta direção orientar-seá no sentido de considerar a participação de um certo número de empresas privadas brasileiras no mercado chinês de insumos energéticos.

Neste sentido, os esforços governamentais desenvolvidos pelos dois países a partir da assinatura do protocolo de cooperação no setor hidroelétrico de 1988, quando da visita do Presidente José Sarney à China, e, sobretudo, após a realização da importante missão empresarial comandada pelo Ministro das Minas e Energia, Alexei Stepanenko, em 1994, resultaram em acordos e na participação de empresas brasileiras em projetos de construção na China.

No entanto, em que pese todos esses esforços, dada a dimensão dos gigantes do mundo em desenvolvimento, parece ser consenso na comunidade política e diplomática que as relações no campo energético, assim como em outras dimensões, encontram-se aquém do potencial de realização efetiva das duas economias. Evidencia-se como obstáculo real o pouco conhecimento mútuo sobre as potencialidades de cada um dos dois parceiros.

Mais uma razão para que o encontro de personalidades brasileiro-chinesas, propiciado por iniciativas como a do Seminário Brasil-China, apresente-se como uma oportunidade a mais de ampliar-se e adensar-se o conhecimento sino-brasileiro.

\section{Brasil e China: unidade e cooperação na política internacional}

"Devido à situação geral em que encontra-se o mundo, em pleno processo de mudança, todos os países estão refletindo sobre a nova política que devem adotar, assim como sobre a nova ordem internacional que se deve estabelecer. Já são inoperantes o hegemonismo, a política de blocos e as organizações de tal ou qual pacto. Então, qual deve ser o princípio a reger as relações internacionais?”

Deng Xiaoping

Ao interrogar-se sobre o princípio que deveria reger as relações internacionais, de quando e como ocorrer a superação do hegemonismo e da política de forças promovida pelas duas superpotências líderes do mundo bipolar, o arquiteto geral da reforma chinesa, Deng Xiaoping, determinou com lucidez a questão maior que comanda a conjuntura mundial finissecular. 
Como é do conhecimento geral, o fim da Guerra Fria foi acompanhado do término da bipolaridade, o que resultou na implosão política que afetou a ex-URSS e o sistema de estados socialistas do Leste Europeu. Em conseqüência deste acontecimento, iniciou-se a transição para uma nova ordem política internacional multipolar. Ocorre, no entanto, que ela tem se processado até agora sob a hegemonia da superpotência norte-americana, cuja liderança visa estabelecer, com sua pretendida superioridade global (econômica, política, militar e cultural), a unipolaridade.

Ao atuar desta forma, os líderes dos EUA e seus aliados mais próximos praticam uma política de força, intervencionista, que tem afetado a vida dos mais diversos países, sobretudo do mundo em desenvolvimento. Quase todos os estados e respectivos governos, independentemente do regime econômico ou social que adotem, desde que fora do âmbito do G-7, vêm sendo objeto de tentativas de intervenção e de ingerência em seus assuntos internos, com crescente ameaça de sanções econômicas e até mesmo de atos de força que violam sistematicamente sua soberania.

Os episódios recentes da crise de Kosovo e do Timor, em que pese as diferenças de latitude e longitude, pareceram ser bem representativos dessa nova disposição da superpotência hegemônica em submeter a soberania nacional dos países médios e pequenos ao princípio de intervenção dita humanitária. Segundo o argumento "humanitário", a defesa de populações civis contra abusos cometidos por autoridades governamentais desobriga as grandes potências de respeitarem a independência desses estados.

Esta disposição em violar os direitos soberanos dos países médios e pequenos recoloca o sistema internacional diante dos velhos arreganhos colonialistas, nostálgicos dos tempos da rainha Vitória e do seu primo, o Kaiser alemão, que se presenteavam mutuamente com parcelas de territórios da África e da Ásia. Com o agravante de, ao concentrar-se o poder mundial nas mãos de uma só liderança (cujo espírito missionário, agravado pelo caráter salvacionista desenvolvido ao longo da Guerra Fria, ainda não foi desmobilizado), recriar-se, a todo momento, situações difíceis e desestabilizadoras para a ordem mundial.

Ao analisar este e outros fatos decorrentes, constatamos que a reestruturação das relações mundiais de poder pós-Guerra Fria segue um receituário baseado na concepção unificadora e pseudo-libertária do modelo anglo-americano. Em continuidade com o passado, temos de volta uma tentativa imperial de padronizar o universo, submetendo, pela força sempre que possível, toda e qualquer manifestação de independência nacional.

E tal como no passado, a imposição do status quo acaba por criar obstáculos ao desenvolvimento de todos os países, pois, a tentativa de unificar o mundo, sob a regra única da Pax Americana, volta-se para o círculo interno das grandes potências, congelando-as junto com o macropoder mundial. Via de conseqüência, abre-se o 
caminho da solução de força, retornando-se ao ciclo intérmino das guerras e revoluções.

Nos graves conflitos, localizados no Golfo, nos Balcãs e na África Central, é possível perceber como esse movimento de reestruturação do poder mundial pós-Guerra Fria, mesmo que parcialmente, revive algumas das condições do início do século XX quando, em um ambiente de extrema competição, as grandes potências agiam em conjunto para manter a situação colonial e semicolonial.

Não por acaso, a Conferência de Haia em 1907 já havia representado um ponto sem retorno na história das relações internacionais contemporâneas. A realização, na passagem do século, das guerras Hispano-Americana e Anglo-Boer e a intervenção das oito potências na China, quando da repressão ao movimento Yihequan (guerra dos Boxers), desenhou uma situação onde a América do Norte e o Extremo Oriente associar-se-íam ao Euromundo, formando um novo centro político mundial. Esta configuração do início do século não foi alterada desde então, pois, a queda do muro e o débâcle da URSS, só fez com que a Rússia aos poucos viesse a reinserir-se à dinâmica do macropoder ocidental.

Na palavra vibrante da Águia de Haia, assim foi caracterizado o novo sistema, que três guerras mundiais e iem umeráveis conflitos não conseguiriam alterar em sua essência: “(...) Atentai bem para as conseqüências, mais terríveis doravante do que em qualquer outra época. Há cerca de três anos, a Europa não divisava em seu horizonte político, fora dela mesma, mais do que os Estados Unidos, como uma espécie de projeção européia e a única representação não negligenciável do Ocidente. A Ásia e a América Latina não passavam de expressões pouco mais que geográficas, com uma situação política complacente. Um belo dia, em meio ao espanto geral, percebeu-se uma aparição aterradora no Oriente. Era o nascimento inesperado de uma grande potência. O Japão entrava no concerto europeu pela porta da guerra, que ele arrombara com sua espada”.

Quase um século decorrido desse episódio, descrito em vivas cores por Rui Barbosa, podemos constatar que a estrutura que ele criticou de forma incisiva mantém-se de pé, impondo os mesmos efeitos e conseqüências sobre a ordem internacional, sobretudo por estimular a continuidade da concentração do poder mundial em mãos de uma pequena parcela da comunidade internacional. Hoje em dia, quando se impõe o poder hegemônico de uma única potência, torna-se mais problemática ainda a criação de uma ordem mundial baseada na igualdade das nações e no respeito à soberania de todos os estados.

O Barão de Rio Branco extraiu toda a conseqüência dos fatos ocorridos na Corte Internacional de Haia ao imaginar um primeiro passo positivo na direção de uma política integrada dos países vizinhos do Brasil. A sua opção realmente se desvela na arquitetura do "Tratado de cordial inteligência política e de arbitramento entre os Estados Unidos do Brasil, a Republica do Chile e a Republica Argentina”, em que o grande chanceler brasileiro, com ousadia e realismo, antecipou a defesa 
coletiva dos interesses e aspirações comuns dos países do ABC e a de todas as questões "que se encaminham a assegurar a paz e a estimular o progresso da América do Sul”.

São questões de grande atualidade que nos levam a pensar na defesa da soberania, segurança e integridade do Brasil e dos demais países sul-americanos frente a um quadro de pressões neo-intervencionistas por parte das potências hegemônicas. Hoje, tal como em 1907, nos deparamos com o fato terrível denunciado por Rui "de que a grandeza internacional se mede apenas pela força das armas".

É neste contexto que se insere a cooperação política dos dois maiores estados do mundo em desenvolvimento, a China e o Brasil, capazes potencialmente de contribuir para a construção de uma nova ordem internacional multipolar e antihegemônica.

Nos anos 90, alguns analistas do poder mundial claramente começaram a demonstrar preocupação com o fato de que a China emergia como potência. A reforma de Deng Xiaoping desencadeara uma nova revolução chinesa com um surpreendente e acelerado processo de criação de um imenso mercado produtor e consumidor. Desse modo, a profecia napoleônica (“...Quando a China despertar o mundo tremerá”) começava a fazer sentido e o Ocidente descobria de repente, entre inquieto e interessado, a existência de uma Nova China. O acelerado processo de industrialização transformava, no espaço de uma geração, um imenso país agrícola em um grande país industrial. Juntamente com o Brasil, que também desenvolvera nos últimos 50 anos uma grande indústria capaz de fabricar aviões, foguetes, submarinos nucleares e satélites artificiais, a China se projetava como um possível mega-estado do século XXI.

Este acontecimento muda certamente a natureza do desafio que se ergue diante dos países em desenvolvimento acerca de como construir uma nova ordem internacional. No momento em que obstáculos se acumulam diante dos países médios e pequenos, alvos de uma nova investida hegemônica em que as grandes potências se armam de recursos econômicos para pressionar em favor dos seus interesses, define-se um protagonismo de alguns dos gigantes do mundo em desenvolvimento.

Pouco a pouco parece inaugurar-se a era do mega-estado e com ela vemos a emergência das grandes regiões subdesenvolvidas que dispõem de possibilidades de atingir o nível das grandes potências. Essas pan-regiões, como o Brasil e a China, podem sustentar a medição de forças com as economias centrais com alguma possibilidade de êxito. Certamente essas possibilidades crescerão ainda mais na medida em que forjarem entre si uma grande unidade e cooperação, estabelecendo condições mais favoráveis de barganha em defesa dos seus interesses econômicos. 
Desde a primeira visita de um presidente brasileiro à China, em 1984, os dois países “desejam assegurar, em grau máximo, a cooperação bilateral. Partem ambos de uma igual dedicação à causa da preservação da paz e segurança mundiais; de respeito aos princípios da autodeterminação e da não interferência em assuntos internos; e da plena aceitação das diferenças existentes na comunidade internacional, composta de países que ostentam sistemas sociais diversos”. Este relacionamento sino-brasileiro, como conceituou o Presidente João Figueiredo, deverá basear-se na "convergência no plano mais alto da política internacional, bem como em projetos e realizações de caráter econômico-comercial, de cooperação e de intercâmbio cultural”.

Cooperação política que foi amplamente debatida com a liderança suprema da China quando ainda vivia o líder Deng Xiaoping e que, após a sua sucessão, tem sido ratificada através de seus atuais dirigentes: Presidente Jiang Zemin e Primeiro Ministro Zhu Rongji. Também tem sido definida como um propósito de pensamento e ação: a de Brasil e China pensarem juntos o mesmo combate pela paz e o desenvolvimento. ${ }^{4}$

\section{Brasil e China face à globalização}

"É através de suas transformações que o "Li" (a estrutura dos seres) torna-se visível.” Wang Fuzhi

A China aparece cada vez mais como um ator relevante do sistema internacional. Maior mercado emergente da economia global, mantém-se como a principal área de crescimento econômico do mundo em desenvolvimento. De acordo com previsões de analistas ocidentais, mantidas as condições atuais, ameaça alcançar o mesmo patamar dos países industrializados em menos de uma geração. De outro lado, o Brasil, que capitaneou o ritmo do desenvolvimento industrial neste século, enfrenta uma prolongada crise que produziu o enfraquecimento e, por hora, a desaceleração do seu processo de industrialização. Tal resultado, que se deseja seja episódico, parece desenhar um cenário de inflexão conjuntural da curva de desenvolvimento brasileiro.

Neste contexto, em meio ao estrépito dos arautos da "globalização" financeira e do "poder soberano e supranacional dos mercados", observamos o Brasil e a China lutarem com seus recursos de poder, enfrentando os mesmos obstáculos, contra a tendência protecionista dos países industrializados, que se valem de pretextos como o "dumping social”, a "defesa do meio ambiente e dos Human Rights”, para tutelar o comércio mundial de bens, capital e trabalho. Para compreender um pouco mais a natureza do processo e reconhecer alguns dos obstáculos que se apresentam no caminho dos gigantes do mundo em desenvolvimento, é preciso fazer uma rápida incursão no passado. 
Se estudarmos o que se passou desde os começos da expansão marítima e comercial da Europa, nos séculos XV, XVI e XVII, veríamos configurar-se as premissas de um mercado mundial, aí onde já aparecem alguns gigantes como: o mundo hispano-americano; o Brasil e os grandes reinos da África; a Índia; a Insulíndia; e, um pouco mais adiante, as 13 colônias inglesas da América. Contudo, apesar dos esforços desenvolvidos e da coragem indômita dos navegadores portugueses, que abriram as rotas oceânicas do globo, foi preciso esperar pelo predomínio franco-anglo-saxão na Ásia Sínica do século XIX, para que o ExtremoOriente viesse a inserir-se na grande onda do euromercado mundial unificado.

As grandes transformações dos Novecentos, este curto/longo século XX na definição dos historiadores contemporâneos, vieram acelerar esse processo, ao determinar alguns acontecimentos que tiveram extraordinário impacto sobre o mundo: a revolução soviética na Rússia, que gerou um sistema de estado baseado na economia planejada; o colapso dos grandes impérios coloniais e semi-coloniais; a revolução do mundo em desenvolvimento com o surgimento dos grandes países de industrialização recente como o Brasil, a China e a Índia; a aceleração do progresso científico-técnico; e a completude do processo de unificação do mercado mundial. Criaram-se, assim, as condições para a emergência de novos eixos dominantes nas relações internacionais.

É que a partir de Yalta, a Europa Ocidental deixava de ser o centro único do poder político mundial. O pós-Segunda Guerra assistira a erosão do predomínio euro-franco-inglês, substituído pelo poder bipolar russo-americano, consagrada afinal a visão tocquevilliana, que profetizara tal desenlace um século atrás. As duas superpotências passariam a disputar a hegemonia mundial até ocorrer a implosão da URSS e de seus aliados do Leste da Europa.

Paradoxalmente, a implosão do mundo soviético ocorreria em decorrência do próprio processo de negociação em torno do impasse nuclear, iniciado ainda nos anos 60-70. Isto levou, de um lado, ao reconhecimento da paridade estratégica entre as superpotências e, de outro, à distensão no conflito Leste-Oeste. Processo cujo curso final, após um segundo momento de retorno e agravamento da Guerra Fria com a crise dos mísseis no teatro europeu, conduziu aos acordos Leste-Oeste que seriam assinados por Bush e Gorbatchov. O paradoxo é que desses acordos resultaram, tanto o término tranqüilo (e relativamente incruento) do macro-conflito mundial travado pelos EUA e pela URSS, como o subseqüente colapso do "sistema socialista do Leste Europeu”. Desfecho esse de um conflito que dividira o Ocidente e que a mídia internacional consagraria ao popularizar a expressão "Queda do Muro”.

O desenlace da Guerra Fria trouxe ainda inúmeros efeitos determinantes sobre a conjuntura mundial. O primeiro e mais óbvio foi a entronização da figura da superpotência única, com o estabelecimento da unipolaridade baseada na supremacia do poder global norte-americano. Um segundo e decisivo foi deslocar 
o eixo do antagonismo político para o sentido Norte-Sul. O terceiro, cujo impacto tem sido aparentemente maior, foi o de promover a reordenação da economia mundial sob a hegemonia de um mercado "globalizado" liderado pelas chamadas "democracias industriais do Ocidente".

Como conseqüência geral desse quadro e do caráter hegemônico da política de supremacia mundial assumida pelos Estados Unidos da América no após-Guerra Fria, as relações internacionais estão sendo profunda e crescentemente marcadas, nesta etapa em que se assiste à "mudança de pele da humanidade finissecular", pela oposição cada vez maior ao duplo "império": o da "globalização econômica" e o da "unipolaridade política". A manobra em curso, de conduzir os destinos do mundo em termos hegemônicos, favorece a concentração mundial dos recursos de poder político e econômico, tanto quanto tecnológico e cultural, e é ruinosa para a criação de um macroclima internacional de distensão e progresso.

Frente a este quadro, a política externa brasileira, inserida na conjuntura mundial, enfrenta um especial desafio, pois, ao tentar fazer avançar a cada momento os seus interesses maiores, depara-se com a intransigência posta pelo poder hegemônico global, o que a obriga a posicionar-se em oposição clara a algumas das tendências dominantes.

Uma dessas tendências que dificultam o relacionamento internacional é a preocupação com a normatização das regras do comércio entre as nações seguindo os princípios da imposição de modelos e de procedimentos, quando o que essas normas deveriam pautar é o intercâmbio e o comércio pelas regras do interesse comum e da busca de parcerias construtivas e mutuamente benéficas, pois, o comércio e a cooperação que não são baseados no reconhecimento de interesses comuns acabam por restaurar o velho "colonialismo", que foi banido da lei internacional por ser incompatível com o estatuto de nações soberanas, tal como está disposto na Carta de São Francisco.

Tanto mais verdade, sobretudo, quando se pretende impor um novo ciclo de predomínio dos países industrializados, baseado no controle financeiro multinacional das economias nacionais. Por intermédio de organismos internacionais, como o Banco Mundial, o Fundo Monetário Internacional e a Organização Mundial de Comércio, são criadas regras e diretrizes que modelam e facilitam a intervenção nas finanças dos países em desenvolvimento, promovidas pelos capitais especulativos multinacionais.

A presença desses capitais na economia global vem gerando um imenso fluxo de recursos financeiros, cujo destino pode ser o de contribuírem para o desenvolvimento das economias nacionais em crescimento. Nesse caso, pode ser creditado ao sistema financeiro um papel positivo na formação da poupança necessária à decolagem do processo de industrialização, o que viria a determinar no futuro a emergência de novos pólos econômicos e de novos centros de poder internacional. 
No entanto, a maioria dos países vive hoje uma situação de permanente crise financeira, resultante do endividamento e da carência de capitais para investimento básico. Todos reclamam dos recursos econômicos insuficientes para a construção mínima da infra-estrutura e de outras necessidades da economia nacional. Para combater tal situação de penúria de capitais é que se procurou fundar uma organização de fomento ao desenvolvimento.

Por isso, a grande iniciativa diplomática brasileira dos anos 60, ao liderar a Conferência das Nações Unidas para o Comércio e o DesenvolvimentoUNCTAD que resultou na criação do grupo dos 77, contribuiu de modo decisivo para criar uma atmosfera favorável ao debate sobre a cooperação e o intercâmbio entre os países meridionais. Esta Conferência, realizada em Genebra em 1964, serviu de base a todos os esforços de criação de uma nova ordem econômica internacional, dando início a uma nova etapa na cooperação Sul-Sul. Desde então, esta idéia transformou-se em um grande instrumento de barganha dos países em luta pelo desenvolvimento.

Os acontecimentos desse final de século parecem configurar um mundo de polaridades difusas a determinar violenta competição internacional. Sob a égide dos Estados Unidos da América, a economia mundial sofre contínuos e constantes choques que se amiúdam, mantendo o mundo em suspense com a ameaça de, a qualquer momento, ser atingido por uma onda capaz de engolfar a economia global em uma crise das mesmas proporções da crise de 1929, o que se afigura como um fim apocalíptico do ciclo econômico, social e político a coincidir com o fim do século e do milênio.

Uma das marcas dessa configuração nova é a chamada "globalização". A verdade que se desvela dessa forma nova alcançada pela economia mundial é de que a continuada deterioração da economia de inúmeros países em desenvolvimento vem aumentando. Com a disparidade entre o Sul e o Norte se ampliando, as complicações geradas por um mundo unipolar apontam para a exigência e a procura da multipolaridade.

O Brasil e a China se inserem nesse contexto como dois países de dimensões continentais, verdadeiras pan-regiões auto-satisfeitas territorialmente, mas desafiadas a desenvolver-se para atingir padrões mais altos de riqueza e poderio nacional. Parece lógico pensar que esse desenvolvimento, ao atingir o seu momento de maturidade, imporá transformações no sistema econômico e político internacional. Não por acaso o desenvolvimento da China, tanto quanto o do Brasil, é avaliado como ameaça potencial ao status quo atual. Trata-se de algo já pensado e meditado, na medida em que ambos estão destinados a formar os mega-estados do século XXI.

Nos últimos dez anos, o conceito de mega-estado tem animado o debate em curso nos meios que estudam o fenômeno da globalização e da unipolaridade 
do ângulo em que pode ser visualizado o interesse nacional brasileiro. Uma das particularidades desse termo é que ele aponta para o surgimento de novos centros de poder mundial fora dos estados da periferia ocidental e oriental, vale dizer, a Europa Ocidental, Central e do Leste e os Estados Unidos.

Releva notar que, em sua essência, o padrão de desenvolvimento sinobrasileiro discrepa do anglo-saxônico e europeu. Parece ser esta a razão pela qual os Estados Unidos, desde o fim da guerra fria, vêm apontando a China como uma ameaça aos interesses norte-americanos. O Brasil, embora não se faça ainda sentir pela máquina de propaganda do Congresso e da Imprensa uma pressão igual que desencadeie as mesmas hostilidades, é visto com a mesma desconfiança, que vem sendo atenuada apenas com continuadas concessões de natureza a comprometer o estatuto político-estratégico nacional, sacrificado muitas vezes ao altar das relações de boa vizinhança.

Assim que, a construção do mega-estado brasileiro, como o chinês, é condição básica para que o desenvolvimento mundial atinja no próximo milênio a plena maturidade, com a expansão dos meios sócio-econômicos, científicostecnológicos e culturais-globais, postos ao alcance de toda a humanidade, o que poderá acontecer em um prazo histórico previsível, anulando e neutralizando as tendências negativas em curso no sistema internacional.

Neste ponto, fundamental é fortalecer a unidade e cooperação entre os países em desenvolvimento, cujos Estados devem buscar a paz mundial, o progresso de suas sociedades nacionais, o florescimento de suas economias nacionais e a elevação do nível de vida de seus povos, pois, a alternativa seria comprometer o desenvolvimento e, com ele, a segurança desses países.

Os rumos que podem tomar esses acontecimentos interpelam mais e mais a opinião pública mundial. Não há como deixar de refletir sobre o fato de que, a continuarem se reproduzindo as condições atuais de competição e concentração do comércio internacional, vale dizer, a férula imposição das regras ditadas pelo interesse de uns poucos países e sociedades ricas no processo da chamada "globalização", ver-se-á logo o retorno rápido e inevitável ao ciclo de violência e guerra entre as nações. Daí a importância da construção de parcerias estratégicas voltadas para a diminuição do efeito concentrador do poder mundial.

Neste sentido, a cooperação sino-brasileira no enfrentamento dos problemas gerados pela "globalização", que podemos julgar ensandecida na sua forma atual porque predadora do ambiente econômico e sócio-político mundial, poderá atuar como uma força de vanguarda na construção de uma nova ordem internacional. Principalmente, quando se depara com ameaças crescentes de implosão do sistema financeiro internacional, motivado pelo novo crack de Nova York.

Para tanto, o relacionamento sino-brasileiro, cujo desenvolvimento aponta para o aparecimento possível de dois mega-estados do século XXI, deverá enfrentar 
o desafio de romper com o monopólio de fato exercido pelas potências hegemônicas em segmentos chave, tanto da economia quanto da política internacional. Brasil e China devem estabelecer uma aliança e cooperação para o novo milênio capaz de garantir que o projeto nacional de ambos tenha condições de realização efetiva, criando dois novos pólos e centros de poder que reconstituam o macroclima mundial no sentido da paz, estabilidade e prosperidade comum.

Desta maneira, face à "globalização ensandecida”, cujo caráter predador se faz presente em todos os horizontes do planeta acarretando sérios problemas para a paz mundial e, sobretudo, à estabilidade institucional dos países em desenvolvimento, podemos talvez visualizar, como possibilidade real, a emergência futura de uma "globalização ilustrada". Como tal deverá ser compreendido o advento de uma "ordem mundial multipolar", com a incorporação dos novos mega-estados resultantes da evolução da política e da economia internacional. Na direção, portanto, de uma nova ordem mundial justa, não hegemônica e democrática. ${ }^{5}$

Nada obstante a grande distância geográfica e cultural que separa os dois gigantes (um no Extremo Oriente e o outro no Extremo Ocidente), é cada vez maior a aproximação e comunicação, como a indicar que o século XXI, tal como anunciado por Deng Xiaoping, não será o século do Pacífico sem a participação do Brasil e da América Latina.

Assegurar em grau máximo a cooperação bilateral face à globalização constituirá certamente um avanço significativo na cooperação estratégica, que fará com a relação sino-brasileira venha a significar um dos eixos da concertarão internacional no próximo milênio.

\section{Conclusões}

"O máximo do savoir-faire consiste não em ganhar todas as batalhas, mas em submeter o exército inimigo sem se bater.”Sunzi

Ao final do encontro Brasil China, organizado pelo Instituto de Pesquisas em Relações Internacionais - IPRI e que reuniu expressivas personalidades da vida política, da alta administração pública, dos meios acadêmicos e, empresariais brasileiras e chinesas, havia um consenso se delineando e uma clara via se abrira na busca de aproximação e conhecimento mútuos e recíprocos.

Consenso quanto ao conteúdo básico da relação entre os dois países que, na seqüência de toda a troca entre os maiores mandatários e lideranças nestes últimos 25 anos, tem se firmado sempre como o de "uma convergência no plano mais alto da política internacional” e de uma procura permanente de realizações comuns na economia, no campo científico e tecnológico e no intercâmbio cultural e acadêmico. 
Percorrendo as avenidas temáticas que pontuaram o recente encontro sino-brasileiro, deparamos com um entrecruzamento de questões entre os dois países que demonstra o quanto têm ambos a ganhar com a cooperação nos vários campos da ação comum. Em todos eles, o esforço de cientistas e técnicos tem elevado a capacidade de mobilização das duas comunidades.

Claro está que o encontro foi realizado sob o impacto do lançamento do satélite sino-brasileiro de recursos naturais, cujo êxito consagrou os esforços desenvolvidos pelas comunidades científicas e autoridades governamentais brasileiras e chinesas. Um acontecimento que, no dizer do Embaixador Roberto Abdenur, veio a ser "a primeira demonstração concreta das virtualidades de uma relação de parceria entre os dois países”. Trata-se do primeiro grande momento do projeto de construção conjunta de satélites artificiais de monitoramento de recursos da terra. Esse empreendimento constitui o acordo de cooperação internacional, no setor de alta tecnologia, mais importante no plano das relações Sul-Sul.

Assim que, nos dois dias de realização do seminário Brasil-China, desfilaram vozes consensuais sobre a importante parceria nos campos da "infra-estrutura, energia e matérias-primas, indústria pesada e serviços de consultoria e engenharia”. Como também se pensou na valorização estratégica que emerge dessa cooperação, sobretudo no enfrentamento dos desafios postos aos países em desenvolvimento pela transformação em curso na ordem econômica e política internacional.

Abril de 2000

\section{Notas}

1 O Seminário Brasil-China foi organizado pelo Instituto de Pesquisa de Relações Internacionais do Itamaraty e contou com a colaboração da Câmara de Comércio e Indústria Brasil-China e do Programa China-Ásia-Pacífico. O Embaixador Samuel Pinheiro Guimarães conseguiu reunir, nos dias 18 e 19 de novembro de 1999, importantes elementos do cenário político e estatal brasileiro-chinês, em um encontro destinado a examinar e avaliar um relacionamento chave para a diplomacia e a política do estado nacional brasileiro.

2 As grandes mudanças no mundo, ocorridas com a abertura chinesa promovida por Deng Xiaoping, inscrevem-se no horizonte da política internacional a partir do histórico encontro que reuniu, em fevereiro de 1972, os dirigentes chineses Mao Zedong e Zhou Enlai com a liderança norteamericana representada pela dupla Nixon-Kissinger.

A cooperação sino-brasileira, inaugurada com o estabelecimento de relações em 1974, ampliouse com a visita presidencial de 1984 e adensou-se significativamente em 1988, com o lançamento do projeto de construção conjunta dos satélites de monitoramento da crosta terrestre.

As visitas ao Brasil efetuadas ao longo da década de 1990, do Presidente Jiang Zemin e do Primeiro Ministro Li Peng, e do então Presidente do Banco Popular da China e atual Primeiro Ministro Zhou Rongji, serviram para consolidar os laços de amizade e cooperação entre os dois países. Foi possível identificar elementos estruturais na relação que apontam para um 
protagonismo no século XXI: China e Brasil são dois mega-estados emergentes e podem sustentar juntos o combate por uma nova ordem econômica e política internacional (Zhong Ba Zhan Lue Hu Ban).

5 Nesse momento em que a divisão e a perplexidade parece rondar algumas das lideranças do país face aos desafios da "globalização", deve-se retomar, atualizando, a forma como os enfrentaram no passado os brasileiros que souberam melhor pensar e agir em defesa das aspirações nacionais. Neste sentido, ninguém mais do que o Barão de Rio Branco pode antecipar o protagonismo nacional no mundo. Em seu discurso, dirigido ao III Congresso Científico Latino-Americano, deixou uma visão do mega-estado brasileiro: “A Nação Brasileira só ambiciona engrandecer-se pelas obras fecundas da paz, com seus próprios elementos, dentro das fronteiras em que se fala a língua dos seus maiores, e quer vir a ser forte entre vizinhos grandes e fortes, por honra de todos nós e por segurança do nosso continente, que talvez outros possam vir a julgar menos bem ocupado."

\section{Bibliografia}

ABDENUR, Roberto. “De Império Imóvel a Superpotência: a trajetória ascendente da China”. Em: OLIVEIRA, Carlos Tavares. China: superpotência do século XXI. Rio de Janeiro: Foglio, 1993. AZEREDO DA SILVEIRA, AF. Discurso em Brasília,15 de agosto de 1974. Em: Brasil-China, 20 anos de relações(1974-1994). Rio de Janeiro: Conjunto Universitário Candido Mendes,1994. BRZEZINSKI, Zbgniev. The grand chessboard. N.York: Basic Books,1997.

CABRAL, Severino. “China e Brasil” Em: Visões da Crise. Rio de Janeiro: Contraponto,1998. . “Conhecer a China hoje”. Tempo Brasileiro, Rio de Janeiro, 137:5/8, abr.-jun.,1999. . “A China rumo ao século XXI (transformações do desenvolvimento)”. Porto Alegre, RSV.23-n-4.

CHEN, Chieh. Discurso em Brasília, 15 de agosto de 1974. Em: Brasil-China, 20 anos de relações (1974-1994). Rio de Janeiro: Conjunto Universitário Candido Mendes,1994.

CHEN, Duqing. “Entrevista”. Tempo Brasileiro, Rio de Janeiro, 137: 5/8, abr.-jun.,1999.

COX. Report of the Select Commitee on U.S.National Security and Military/ Commercial concerns with the People's Republic of China. Washington: Regnery Publishing, 1999.

DENG, Xiaoping. Textos Escogidos, v.3. Beijing: Ediciones en Lenguas Extrangeras,1994.

FIGUEIREDO, João Baptista: “Discurso em Beijng”, 17 de maio de 1984. Documento do Arquivo do Itamaraty.

FUNG, Yu-Lan: Selected Philosophical Writings. Beijing: Foreign Languages Press, 1998. GEISEL, Ernesto. Depoimento ao CPDOC. Rio de Janeiro: Fundação Getulio Vargas,1997. GERNET, Jacques. L'Intelligence de la Chine: le social et le mental. Paris: NRF, 1994.

GUIMARÃES, Samuel Pinheiro. Quinhentos anos de periferia. Porto Alegre: Editora da Universidade/ Contraponto, 1999.

. Estratégias Índia e Brasil. Brasília: Instituto de Pesquisa de Relações Internacionais; Fundação Alexandre de Gusmão,1997.

HUNTINGTON, Samuel. The Clash of Civilizations. N.York: Simon \& Shuster,1998. . The lonely superpower. N. York: Foreign Affairs

JIANG, Zemin. “Discurso em Brasília, 23 de novembro de 1996”. Documento do Arquivo Itamaraty. KISSINGER, Henry. Nuclear weapons and foreign policy. N.York: Norton, 1969. 
LAMPREIA, Luiz Felipe. Diplomacia brasileira. Rio de Janeiro: Lacerda \& Editores,1999. LI, Peng: "Discurso em Brasília”, 08 de novembro de 1996. Documento do Arquivo Itamaraty. LIEBERTHAL, Kenneth. Governing China. N.York: Norton,1995.

QIAN, Liren. “Towards a Multi-polar World”. Em: Seminário Brasil-China. Rio de Janeiro: Instituto de Pesquisa de Relações Internacionais - Fundação Alexandre Gusmão, 1999.

RICUPERO, Rubens. Rio Branco; o Brasil no mundo. Rio de Janeiro: Contraponto/ Petrobrás, 2000.

SAN TIAGO DANTAS, F.C. Política externa independente. Rio de Janeiro: Civilização Brasileira,1962.

SARNEY, José. “Discurso em Beijing”, 04 de junho de 1988. Documento do Arquivo Itamaraty. SUNZI. L'art de la guerre. Beijing: Editions Chine Populaire, 1994.

WU, Jie. On Deng Xiaoping thought. Beijing: Foreign Language Press, 1996.

XUNZI, Siun Tseu. Paris: La Cerf,1987.

ZHU, Rongji. “A reforma e abertura da China e as relações entre a China e a América Latina. Palestra proferida na sede da Federação das Indústrias do Estado de São Paulo-FIESP, em 31 de maio de 1993.

\section{Resumo}

O texto analisa a cooperação estratégica sino-brasileira dentro do amplo contexto da política exterior do Brasil, enfatizando seus aspectos bilaterais e sua relação com a ordem mundial pós-Guerra Fria.

\section{Abstract}

The article analyses the strategical cooperation between Brazil and China in the framework of Brazilian foreign policy, emphasizing bilateral aspects and the relations with the World Order after the Cold War.

Palavras-chave: Brasil. China. Cooperação. Política Exterior. Key-words: Brazil. China. Cooperation. Foreign Policy. 